\title{
Postnatal Treatment With Dexamethasone Perturbs Hepatic and Cardiac Energy Metabolism and Is Associated With a Sustained Atherogenic Plasma Lipid Profile in Suckling Rats
}

\author{
YAN LIU, RICK HAVINGA, VINCENT W. BLOKS, JUUL F. BALLER, FEIKE R. VAN DER LEIJ, DIRK-JAN REIJNGOUD, \\ PIETER J. J. SAUER, AND FOLKERT KUIPERS \\ Department of Pediatrics, Center for Liver, Digestive, and Metabolic Diseases, University Medical Center Groningen, 9713 GZ \\ Groningen, The Netherlands
}

\begin{abstract}
Early exposure to glucocorticoids (GC) has been proposed to disturb hepatic and cardiac function in later life. In the present study, we evaluated early metabolic alterations upon GC treatment that may predispose to long-term abnormalities. Rats were injected with dexamethasone (DEX) at d 1, 2, and 3 after birth and controls received saline (SAL). Rats were killed at 2, 7, and $14 \mathrm{~d}$ of age. Compared with SAL, DEX induced lower plasma insulin levels, hyperglycemia, hyperketonemia, and dyslipidemia at $2 \mathrm{~d}$. At the same time, DEX treatment significantly increased expression of gluconeogenic and fatty acid oxidation genes in liver and expression of genes involved fatty acid utilization in heart. At 7 d, DEX-treated rats showed insulin resistance with hyperlipidemia, whereas hepatic and cardiac gene expression patterns were largely normalized. Hyperlipidemia and a significantly increased hepatic triglyceride content in DEX-treated rats were prominent at $14 \mathrm{~d}$ without large differences in hepatic and cardiac gene expression patterns. Thus, neonatal DEX administration transiently affects cardiac and hepatic gene expression patterns in suckling rats associated with sustained effects on plasma glucose and lipid concentrations. Whether these early effects of DEX contribute to hepatic and cardiac abnormalities at adult age needs further evaluation. (Pediatr Res 61: 165-170, 2007)
\end{abstract}

$\mathrm{G}^{\mathrm{c}}$ are used to prevent chronic lung disease in immature newborns because of their anti-inflammatory action. However, despite the evident short-term benefit, concern has emerged about potential long-term negative consequences $(1,2)$. Cardiovascular disease is one of the negative consequences proposed to occur after neonatal DEX administration in preterm human newborns, including transient cardiac hypertrophy (3) and hypertension (4). Recent studies conducted in rats have revealed that neonatal DEX administration leads to cardiac dilatation and reduced systolic function at $4 \mathrm{wk}(5)$ and to cardiac hypertrophy at $45 \mathrm{wk}$ of age (6). So far, the molecular mechanism by which postnatal administration of

Received July 7, 2006; accepted September 24, 2006.

Correspondence: Folkert Kuipers, Ph.D., Center for Liver, Digestive, and Metabolic Disease, Rm Y2.145. Department of Pediatrics, University Medical Centre Groningen, Research Laboratory CMCV-2, Hanzeplein 1, 9713 GZ Groningen, The Netherlands; e-mail: f.kuipers@med.umcg.nl

This study was supported by the Groningen University Institute for Drug Exploration (GUIDE), The Netherlands.

Supplemental material online at www.pedresearch.org

DOI: $10.1203 /$ pdr.0b013e31802d89ff
GC induces cardiac dysfunction later in life has remained unknown.

Epidemiologic studies have raised the "fetal origins of adult disease" hypothesis, stating that early lifestyle factors, imposed by intrauterine or neonatal environment, increase the risk of developing cardiovascular disease and hypertension in later life (7). In particular, exposure to excess GC during critical early life stages has been implicated as a factor that may program long-term changes in cardiac function, predisposing to adult disease (8).

The heart requires a continuous energy supply to maintain its contractile function, while its capacity to store energy-rich substrates is limited. Under resting conditions, the adult heart derives about $70 \%$ of its energy from lipid oxidation and the remainder from glucose (9). Several recent studies have demonstrated that altered cardiac energy utilization might be a cause for cardiomyopathy $(10,11)$. However, whether cardiac genes involved in energy metabolism are persistently affected during that process has not been reported.

GC administration leads to insulin resistance, hyperglycemia, and dyslipidemia in preterm babies (12) and in experimental animals (13). The liver performs a crucial role in maintaining lipid and glucose homeostasis. GC administration may lead to hepatic insulin resistance, contributing to hyperglycemia as well as dyslipidemia in rats (14). Data accumulated in recent years have indicated that GC exposure during early life may cause liver dysfunction in later life, contributing to metabolic derangements $(8,15)$ and increased risk for cardiovascular disease. Therefore, neonatal GC administration may disturb hepatic energy metabolism with a consequently unbalanced cardiac energy supply. However, available data on hepatic energy metabolism, especially gene expression at neonatal stage, are still quite limited.

In the present study, we investigated the short-term effect of GC, particularly of DEX, on hepatic and cardiac expression of genes involved in energy metabolism in relation to plasma concentrations of metabolic substrates in suckling rats, trying

\footnotetext{
Abbreviations: ANF, atrial natriuretic peptide; CPT, carnitine palmitoyltransferase; DEX, dexamethasone; G6PHT, glucose-6-phosphatase transport protein 1; GC, glucocorticoids; PEPCK, phosphoenolpyruvate carboxykinase 1, cytosolic; PPAR, peroxisome proliferator-activated receptor; SAL, saline; TnnT2, troponin T; UCP-2 and 3, uncoupling protein 2 and 3
} 
to identify early signs that may predispose to heart disease in later life.

\section{MATERIALS AND METHODS}

Animals. Pregnant Wistar rats (270-300 g) were housed individually and kept under conventional housing conditions with free access to food and water. Pups were born naturally on d 21-22 of gestation. On the day of birth (d 0), male pups were selected and randomly divided into treatment or control groups fed by "foster mothers" (six pups per litter). Temperature and humidity were kept constant and the dams had free access to food and water. An artificial 12-h light/12-h dark cycle was used. Pups in the treatment group were injected intraperitoneally with DEX 21-phosphate at $\mathrm{d} 1,2$, and $3(0.5$, 0.3 , and $0.1 \mu \mathrm{g} / \mathrm{g}$ body weight, respectively) after birth in the morning from 0900 to $1000 \mathrm{~h}$. Controls were injected with equal volumes $(10 \mu \mathrm{L} / \mathrm{g})$ of sterile pyrogen-free SAL. Pups were killed by decapitation at 2, 7, and $14 \mathrm{~d}$ of age after birth ( $n=11-12$ per group) after samples of blood were collected from the abdominal artery under anaesthesia between 0900 and $1200 \mathrm{~h}$.

All experimental procedures were approved by the local ethical committee for animal experiments.

Analysis. Blood glucose was measured by the Medisense Precision glucose meter (Medisense Precision, Abbott Laboratories, Abbott Park, IL) immediately after blood sampling. The remainder was centrifuged and plasma was separated and stored at $-20^{\circ} \mathrm{C}$ until analysis. Plasma concentrations of total and free cholesterol and of triglycerides were measured with commercially available kits, as previously described (16). Pooled plasma samples from 10 rat pups per treatment group per age were used for lipoprotein separation by fast protein liquid chromatography (FPLC) (17). Plasma insulin concentration was measured by Luminex-based bead array method using LINCOplex simultaneous multi-analyte detection system (Millipore, Billerica, MA) following the manufacturer's instructions. Plasma concentrations of ketone bodies were measured by commercially available kits on a Selectra 2 auto analyzer (Merck, Darmstadt, Germany). Hepatic lipid content was measured as previously described (16) after Bligh and Dyer (18) extraction.

Morphologic analysis. Liver and heart were examined after periodic acid-Schiff (PAS) staining for glycogen $(n=6$ per group) and Oil-red-O (ORO) staining for neutral lipids $(n=4$ per group). Hematoxylin-eosin (H\&E) staining was used for heart morphology ( $n=6$ per group). H\&E and PAS staining were performed on $4 \%$ formalin-fixed, paraffin-embedded sections by standard procedures. ORO staining was performed on frozen sections by standard procedures.

RNA isolation and quantitative real-time PCR. Heart and liver tissues used for RNA isolation were rapidly excised and frozen in liquid nitrogen ( $n=11-12$ each group). RNA was extracted from heart and liver samples by using TRI reagent (Sigma Chemical Co., St. Louis, MO). The integrity of RNA was assessed using Lab-on-a-Chip 2100 Bioanalyzer (Agilent Technologies, Santa Clara, CA). Total RNA was reverse transcribed as described previously (19). Real-time quantitative PCR was performed using an ABI PRISM 7700 sequence detector (Applied Biosystems, Foster City, CA). Primers were obtained from Invitrogen (Carlsbad, CA). Fluorogenic probes, labeled with 6-carboxy-fluorescein and 6-carboxy-tetramethyl-rhodamine, were made by Eurogentec (Seraing, Belgium). Primer sequences are listed in Table 1 (See supplemental material online) and published sequences are listed on our web site at www.labpediatricsrug.nl. Heart gene expressions were standardized by "normalization factors" calculated by GeNorm (20) software from the following house keeping genes: $\beta$-actin, 18S, 36B4, and cyclophilin, because none of these genes alone was sufficiently stable as standard calculated by GeNorm. All hepatic gene expression data were standardized to $\beta$-actin mRNA.

Data analysis. Data were expressed as mean \pm SD. Statistical analysis of groups was assessed by $t$ test or Mann-Whitney $U$ test. Differences within group were assessed by one-way ANOVA. Level of significance was set at $p<0.05$. Analyses were performed using SPSS for Windows software (SPSS, Chicago, IL).

\section{RESULTS}

Neonatal DEX treatment leads to growth retardation in suckling rats. Compared with SAL-treatment, neonatal DEX administration led to a significantly reduced body weight gain, which was manifest already at $24 \mathrm{~h}$ after initiation of DEX treatment. A significantly lower body weight was found during the entire experimental period (2-14 d of age) (Fig. 1). A significantly lower heart weight was noted following DEX

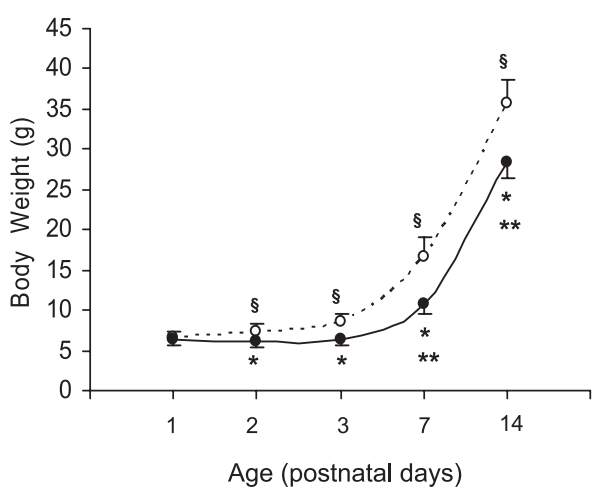

Figure 1. Effects of DEX on body weight. DEX administration (closed symbols) induces significant growth retardation compared with control group (open symbols). $n=12-35$ per group. Values are means \pm SD. $* p<0.05$ DEX $v s$ age-matched controls. $* * p<0.05$ within DEX-treated group compared with d 1. $\S p<0.05$ within SAL treated group compared with $\mathrm{d} 1$.

administration at all ages (Table 2). A significantly higher heart weight/body weight ratio was, however, found only at $7 \mathrm{~d}$ old rats upon DEX treatment, suggesting transient cardiac hypertrophy at that age. Neonatal DEX treatment led to a significantly higher liver weight/body weight ratio at $2 \mathrm{~d}$ of age.

Acute and chronic effects of neonatal DEX treatment on plasma insulin and glucose levels. Hyperglycemia was found at $\mathrm{d} 2$ in rats treated with DEX, however, blood glucose levels decreased to the control level at $7 \mathrm{~d}$ and a significantly lower blood glucose level was found at $14 \mathrm{~d}$ of age (Table 3). Compared with the SAL-treated rats, DEX-treated rats showed significantly decreased plasma insulin levels at $2 \mathrm{~d}$ of age. Elevated plasma insulin was found at 7-d-old rat pups after DEX treatment, which, combined with normal blood glucose level, indicates an insulin resistant state. No differences in plasma insulin levels were found between SAL- and DEX-treated groups at $14 \mathrm{~d}$ of age.

Acute and chronic effects of neonatal DEX treatment on blood lipid profile and ketone bodies concentrations. DEX treatment led to a sustained increase in total plasma cholesterol concentrations (Table 3). Separation of plasma lipoproteins by FPLC revealed that increased cholesterol at $2 \mathrm{~d}$ of age was mainly confined to LDL- and HDL-sized fractions (Fig. 2A). In contrast, at 7 and $14 \mathrm{~d}$, cholesterol was more abundantly present in VLDL and LDL-sized fractions (Fig. 2, $C$ and $E$ ). Plasma triglyceride concentrations were low in 2-d-old DEXtreated rats (Table 2), mainly due to reduction in VLDL-sized fractions (Fig. 2B). Significantly elevated plasma triglyceride concentrations were observed at $7 \mathrm{~d}$ after DEX treatment, with particularly increased amounts of triglycerides in VLDL-sized fractions (Fig. 2D). No difference was found in plasma triglyceride concentration at $14 \mathrm{~d}$ between SAL- and DEXtreated groups (Table 2). At this point, plasma triglycerides were still predominantly associated with VLDL and less with LDL- and HDL-sized fractions in DEX-treated rats compared with controls (Fig. 2F). Plasma concentrations of nonesterified fatty acid (NEFA) and ketone bodies were increased in DEXtreated group at $2 \mathrm{~d}$ of age, yet, no significant differences existed at 7 and $14 \mathrm{~d}$ between both groups. 
Table 2. Effects of DEX on heart and liver weight, heart weight/body weight and liver/body weight ratios at different postnatal ages

\begin{tabular}{|c|c|c|c|c|c|c|}
\hline & \multicolumn{2}{|c|}{ Day 2} & \multicolumn{2}{|c|}{ Day 7} & \multicolumn{2}{|c|}{ Day 14} \\
\hline Heart weight (mg) & $55.1 \pm 5.4$ & $40.5 \pm 2.7^{*}$ & $122.9 \pm 14.1$ & $93.5 \pm 10.9^{*}$ & $205.2 \pm 13.3$ & $172.8 \pm 15.0^{*}$ \\
\hline Heart weight/body weight $(\mathrm{mg} / \mathrm{g})$ & $7.12 \pm 0.75$ & $7.45 \pm 0.71$ & $7.47 \pm 0.72$ & $8.65 \pm 1.02 *$ & $5.79 \pm 0.53$ & $6.13 \pm 0.60$ \\
\hline Liver weight/body weight (mg/g) & $38.53 \pm 1.98$ & $57.48 \pm 2.69^{*}$ & $32.99 \pm 1.31$ & $34.73 \pm 3.86$ & $28.72 \pm 1.92$ & $28.73 \pm 2.36$ \\
\hline
\end{tabular}

Values are expressed as means $\pm \mathrm{SD}$. $(n=11-12$ per treatment group per age).

$* p<0.05$ DEX $v s$ age-matched control.

Table 3. Effects of DEX on concentrations of blood glucose, plasma insulin, triglyceride, cholesterol, NEFA and ketone bodies at different postnatal ages

\begin{tabular}{|c|c|c|c|c|c|c|}
\hline & \multicolumn{2}{|c|}{ Day 2} & \multicolumn{2}{|c|}{ Day 7} & \multicolumn{2}{|c|}{ Day 14} \\
\hline Plasma insulin (pM) & $298 \pm 146$ & $175 \pm 63$ & $175 \pm 71$ & $342 \pm 153^{*}$ & $50 \pm 18$ & $51 \pm 23$ \\
\hline Plasma cholesterol (mM) & $2.27 \pm 0.20$ & $3.23 \pm 0.25^{*}$ & $4.25 \pm 0.28$ & $6.55 \pm 0.60^{*}$ & $4.14 \pm 0.45$ & $5.03 \pm 0.33 *$ \\
\hline Plasma triglyceride (mM) & $0.82 \pm 0.18$ & $0.56 \pm 0.08^{*}$ & $1.56 \pm 0.60$ & $3.95 \pm 1.16^{*}$ & $1.82 \pm 0.30$ & $2.33 \pm 0.98$ \\
\hline Plasma NEFA (mM) & $1.09 \pm 0.13$ & $1.49 \pm 0.07 *$ & $1.68 \pm 0.17$ & $1.98 \pm 0.36$ & $2.26 \pm 0.33$ & $2.13 \pm 0.39$ \\
\hline
\end{tabular}

Values are the means $\pm \mathrm{SD}(n=6-12$ per treatment group per age).

$* p<0.05$ DEX $v s$ age-matched SAL-treated control.

Effects of DEX treatment on hepatic fatty acid and glucose metabolism. Hepatic triglyceride content was significantly decreased at 2- and 7-d-old DEX-treated animals, whereas triglyceride accumulation (steatosis) was clearly present at $14 \mathrm{~d}$ (Fig. 3). ORO staining revealed uniformly distributed fat droplets in liver of DEX-treated rats (Fig. 4, $A$ and $B$ ). PAS staining revealed that DEX treatment led to hepatic glycogen accumulation at $\mathrm{d} 2$ (not shown) and reduced amounts at $14 \mathrm{~d}$ of age (Fig. 4, $C$ and $D$ ).

DEX led to increased hepatic mRNA levels of genes involved in fatty acid uptake and control of fatty acid oxidation
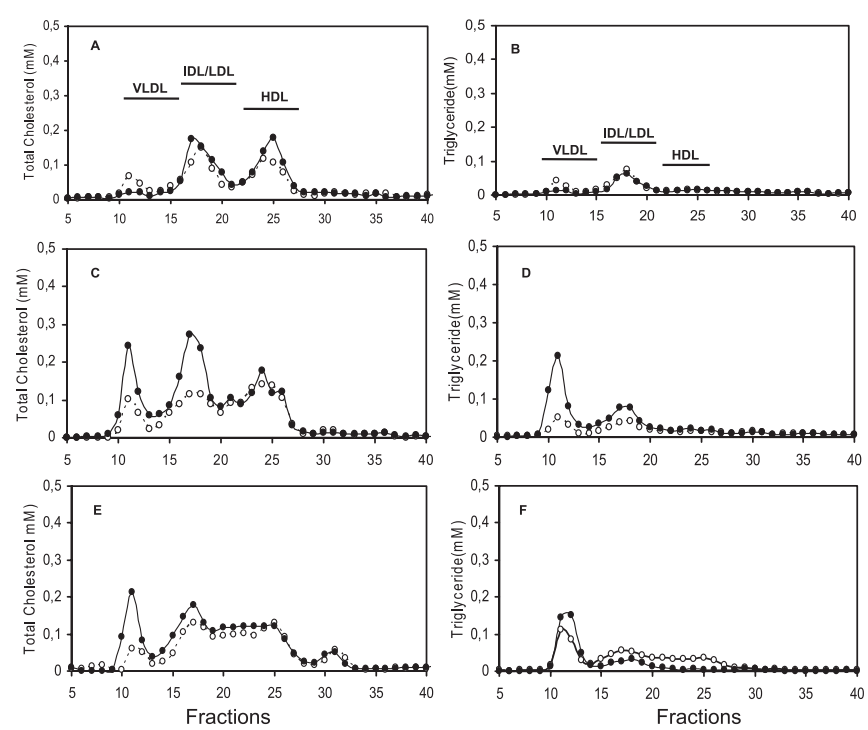

Figure 2. Fast protein liquid chromatography separation of plasma cholesterol $(A, C, E)$ and triglyceride $(B, D, F)$ from the SAL- (open symbols) and DEXtreated (closed symbols) rats at different ages. Plasma samples were pooled $(n=$ $10)$ at each age. $A$ and $B: 2 \mathrm{~d} ; C$ and $D: 7 \mathrm{~d} ; E$ and $F: 14 \mathrm{~d}$ of age. such as PPAR $\alpha$ and carnitine palmitoyltransferase $1 \mathrm{~A}$ (CPT1A) at $2 \mathrm{~d}$ of age, suggesting enhanced hepatic fatty acid oxidation (Fig. 5). In contrast, at $7 \mathrm{~d}$, some of these genes were down-regulated, which may be due to a suppressive effect of elevated plasma insulin at that age. Decreased expression of lipogenic genes such as fatty acid synthase (FAS) was noted at $2 \mathrm{~d}$, and sterol regulatory element binding protein 1c (SREBP1c) at 2 and $7 \mathrm{~d}$ with DEX treatment. All these alterations were transient and normalized at $14 \mathrm{~d}$ of age.

Compared with SAL, DEX increased expression of hepatic gluconeogenic genes at $2 \mathrm{~d}$ of age, as characterized by upregulation of PEPCK and G6PHT expression. Increased expression of some other important genes such as glycogen synthase (GS), glucokinase (GK), and glycogen phosphorylase (GP), together with up-regulated G6PHT, at the mRNA level suggests increased rates of hepatic glucose and glycogen cycling at that age. However, although hepatic PEPCK mRNA continued to be higher in 7-d-old DEX-treated rats, decreased

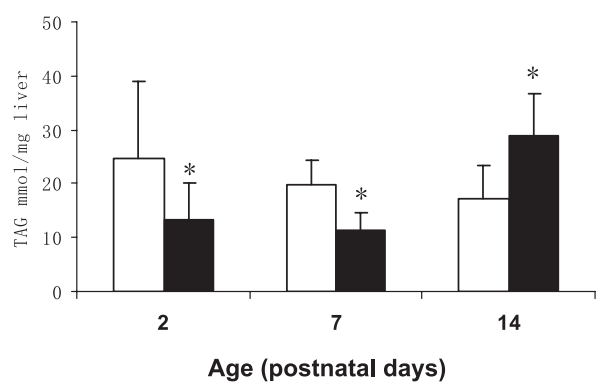

Figure 3. Effects of DEX on hepatic triglyceride content. Compared with controls, DEX administration results in significantly reduced triglyceride in 2 and $7 \mathrm{~d}$, but an increased triglyceride at $14 \mathrm{~d} . n=10$ per group. Values are the means \pm SD. SAL-treated group (open bars), DEX -treated group (closed bars). $* p<0.05$ DEX $v s$ age-matched control. 


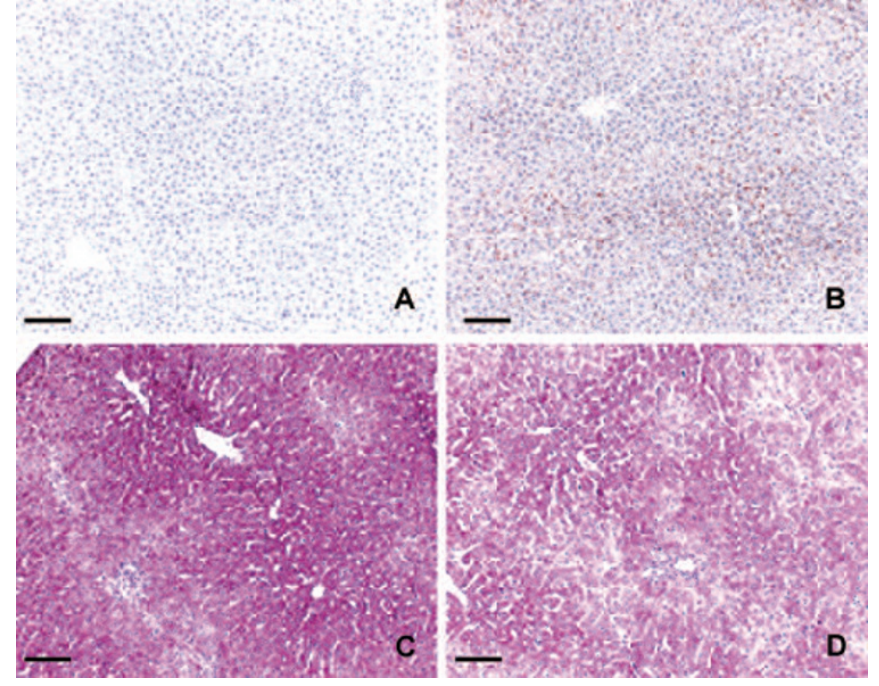

Figure 4. PAS staining shows reduced hepatic glycogen at $14 \mathrm{~d}$ with DEX treatment compared with age-matched control. $n=6$ per group. A: SAL; $B$ : DEX. ORO staining shows accumulated neutral fat in liver sections from DEX-treated rats at d 14 compared with control. $n=4$ per group. $C$ : control; $D$ : DEX. Scale bars: $20 \mu \mathrm{m}$.
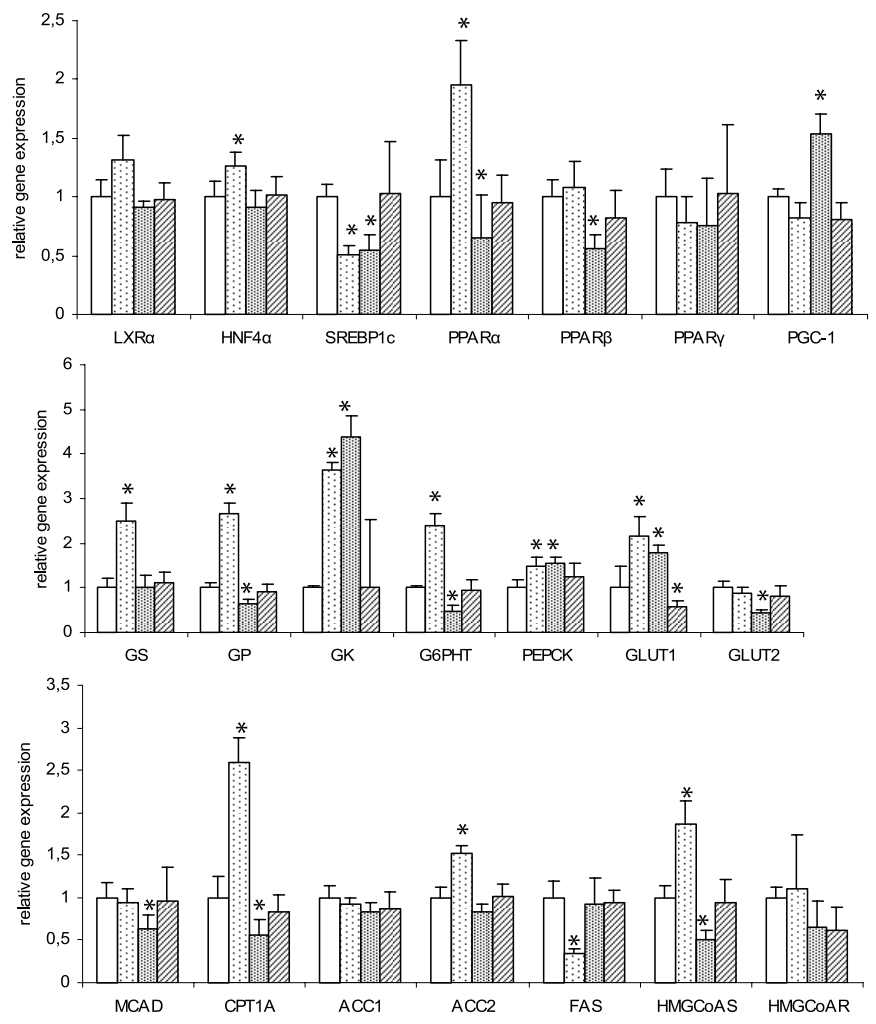

Figure 5. Effects of DEX on hepatic gene expression involved in fatty acid and glucose metabolism at different ages compared with SAL: SAL group ( $\square$ ) is set at 1, $2 \mathrm{~d} \operatorname{DEX}(\square), 7 \mathrm{~d}$ DEX (戒), and $14 \mathrm{~d} \operatorname{DEX}(\mathbb{C}) .{ }^{*} p<0.05 \mathrm{DEX}$ vs age-matched control. $n=7$ per group. $A C C 1$ and 2, acetyl-CoA carboxylase 1 and 2; FAS, fatty acid synthase; $G K$, glucokinase; GLUT1 and GLUT2, glucose transporter 1 and 2; GP, glycogen phosphorylase; GS, glycogen synthase; HMGCoAR, hydroxymethylglutaryl-CoA reductase; $H M G C o A S$, hydroxymethylglutaryl-CoA synthase, mitochondrial; $H N F 4 \alpha$, Hepatic nuclear factor $4 \alpha ; L X R \alpha$, liver X receptor alpha; $M C A D$, medium chain acyl-CoA dehydrogenase; $P G C$-1, peroxisome proliferator-activated receptor gamma, co-activator $1 ; P P A R \alpha$, [gerds], $\beta \gamma$, peroxisome proliferator-activated receptor alpha, beta, gamma.

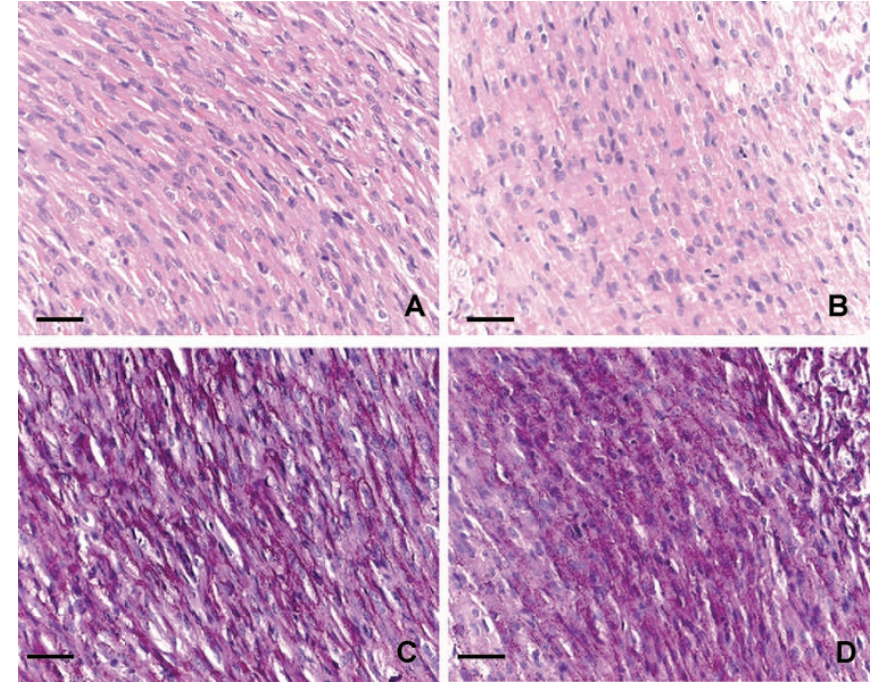

Figure 6. $\mathrm{H} \& \mathrm{E}$ and PAS staining of heart sections from 7-d-old rats. H\&E staining showed hypertrophy in DEX-treated rats. A: SAL; B: DEX. There were no obvious differences found in PAS staining between two groups. $C$ : SAL; $D$ : DEX. $n=6$ per group. Scale bars: $10 \mu \mathrm{m}$.

G6PHT and glycogen phosphorylase (GP) suggest the decease in glycogen degradation. None of these genes was found to be differently expressed in the liver of 14-d-old rats of both groups (Fig. 5).

Effects of neonatal DEX treatment on expression of cardiac genes involved in energy metabolism. Confirming a previous study (21), H\&E staining indicated the presence of enlarged cardiomyocyte in 7-d-old rat pups treated with DEX compared with controls (Fig. 6, $A$ and $B$ ), without differences in PAS (Fig. 6, $C$ and $D$ ) or ORO staining (data not shown).

Cardiac expression of genes involved in control of fatty acid and lipoprotein uptake and metabolism such as PPAR $\alpha$, PPAR[gerds], lipoprotein lipase (LPL), CD36, CPT1A, CPT1B, very LDL receptor (VLDLR), LDL receptor (LDLR), long-chain acyl-CoA dehydrogenase (LCAD), medium chain acyl-CoA dehydrogenase (MCAD), uncoupling protein (UCP) 2 and 3 was found to be significantly increased in hearts of 2-d-old DEX-treated rats, which indicates acute stimulatory effects of DEX on cardiac fatty acid utilization (Fig. 7). Expression of most of these genes, however, was reduced to control levels at d 7. DEX enhanced cardiac expression of genes involved in glucose transport and glycolysis such as glucose transporter 1 and 4 (GLUT1 and 4), and hexokinase 2 (HK2) at $2 \mathrm{~d}$ of age. Particularly cardiac pyruvate dehydrogenase kinase isoenzyme 4 (PDK4) mRNA was increased by DEX. These effects were transient and no significant differences between the groups were seen at $14 \mathrm{~d}$. Increased cardiac gene expression of insulin receptor (IR) at mRNA level was only observed in 2-d-old rats upon DEX treatment.

Postnatal DEX treatment led to an increase in cardiac atrial natriuretic peptide (ANF), desmin, and troponin T (TnnT2) mRNA content at $2 \mathrm{~d}$ of age. Thereafter, cardiac ANF and TnnT2 mRNA levels returned to control level at $14 \mathrm{~d}$ of age, whereas desmin mRNA content was slightly decreased in DEX-treated rats at that time point. 

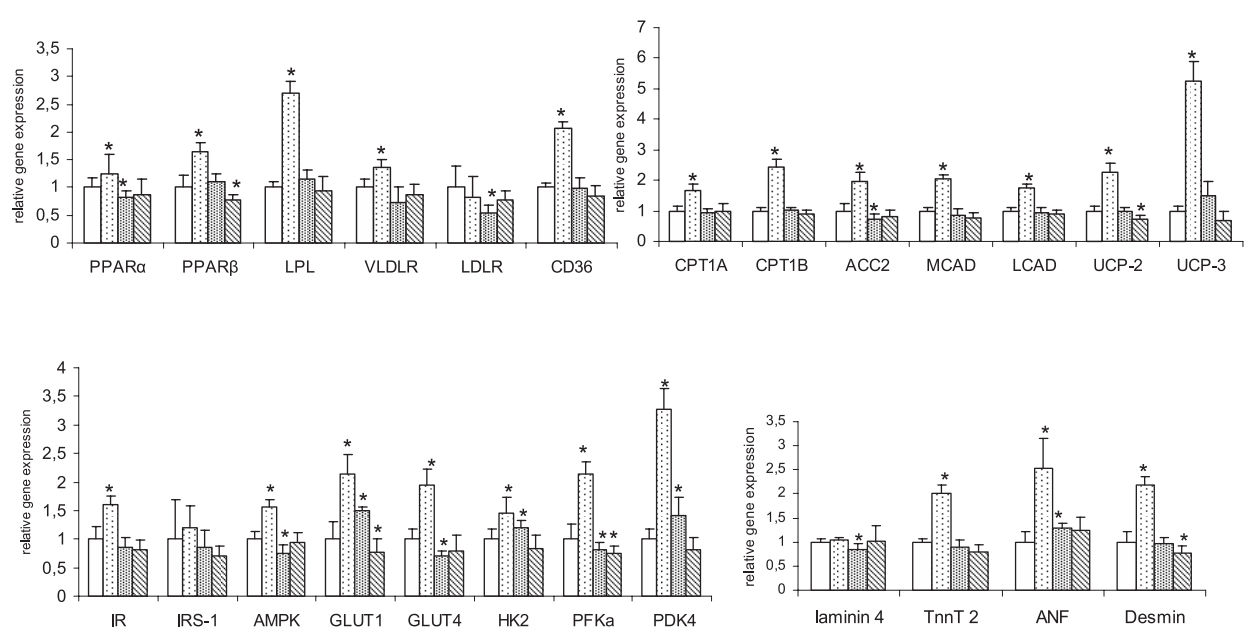

Figure 7. Effects of DEX on cardiac gene expression involved in fatty acid, glucose metabolism, and structure at different ages compared with SAL. SAL group ( $\square$ ) is set at 1, $2 \mathrm{~d}$ DEX (口), $7 \mathrm{~d}$ DEX (国) and $14 \mathrm{~d}$

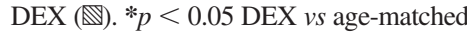
SAL-treated control. $n=6-12$ per group. $A M P K$, AMP-activated protein kinase; $C D 36$, CD36 antigen; $C P T 1 A$ and $B$, carnitine palmitoyltransferase A and B; GLUT4, glucose transporter 4; HK2, hexokinase2; $I R$, insulin receptor; IRS-1, insulin receptor substrate $1 ; L C A D$, long-chain acyl-CoA dehydrogenase; $L D L R$, LDL receptor; $L P L$, lipoprotein lipase; $P D K 4$, pyruvate dehydrogenase kinase isoenzyme 4; $P F K a$, phosphofructokinase, muscle, A-type; $V L D L R$, very LDL receptor.

\section{DISCUSSION}

Treatment of rat pups postnatally with DEX resulted in acute changes in energy metabolism, both with respect to substrate availability and hepatic and cardiac gene expression profiles. In a substantial number of cases, these changes were transient, i.e. no differences were observed between DEX- and SAL-treated groups at the age of $14 \mathrm{~d}$. On the other hand, there were effects of early overexposure to DEX that persisted until $14 \mathrm{~d}$ of age, particularly at the level of plasma and hepatic metabolite concentrations. As a consequence, early exposure to DEX resulted in marked alterations in plasma lipoprotein composition at $14 \mathrm{~d}$ of age and a clear hepatic steatosis.

As reported previously (22), early exposure to DEX resulted in impaired growth: no catch-up growth occurred during the initial $14 \mathrm{~d}$ of life. In fact, it has been reported that neonatal exposure to DEX leads to sustained reduction in body weight gain which might be due to suppression of growth hormones and the IGF axis $(23,24)$. In the present study, both liver and heart weight were reduced in DEX-treated animals, however, upon normalization to body weight, no differences between DEX- and SAL-treated rats were observed except an increased heart/body weight ratio at $7 \mathrm{~d}$ of age. Microscopic examination indicated the presence of cardiac hypertrophy at this time point. There were no apparent signs of cardiac glycogen or fat accumulation observed upon PAS or ORO staining at any age between SAL- and DEX- treated animals.

DEX treatment acutely led to an increase in plasma nonesterified fatty acid concentrations that might be attributable to enhanced lipolysis caused by lower plasma insulin levels. The latter may be a consequence of acute inhibitory effects of DEX on insulin secretion (25). Lower plasma insulin levels, in turn, might reduce glucose uptake by peripheral tissue. Yet, consistent with previous studies (26), DEX administration induced hepatic gluconeogenesis by up-regulating PEPCK and G6PHT gene expression at $2 \mathrm{~d}$ of age. Reduced glucose uptake by peripheral tissue and increased hepatic gluconeogenesis likely contribute to hyperglycemia at this time point. Interestingly, the cycling between glucose and glucose-6-phosphate, glucose-1-phosphate, and glycogen appeared to be increased as deduced from gene expression profiles, confirming a study conducted by Wajngot et al. (27) in healthy human subjects treated with DEX. This might reflect a regulatory mechanism to limit net hepatic glucose production. In addition, decreased fatty acid synthesis and increased fatty acid oxidation induced by DEX treatment, suggested by the expression level of responsible genes, might contribute to lower hepatic triglyceride content at this age. As reported previously (13), DEX led to an insulin resistant state at $7 \mathrm{~d}$ of age, as characterized by increased plasma insulin concentration and sustained increased hepatic gene expression of PEPCK, although blood glucose level was still kept at normal levels. Hyperinsulinemia might be caused by increased insulin secretion, which has also been found by Nicod et al. (28) in human studies. The molecular mechanism behind these observations is still unclear. Hypertriglyceridemia is frequently encountered in patients with insulin resistance. Data suggest that it is due to an inability of insulin to suppress hepatic VLDL secretion (29). There were no differences in hepatic "lipid" gene expression between SAL- and DEX-treated animals at $14 \mathrm{~d}$ old, indicating no persistent alteration in hepatic gene expression to occur in this experimental setting. However, increased VLDLassociated cholesterol and triglycerides, i.e. an atherogenic lipid profile (30), persistent until this age. Significantly reduced blood glucose concentration in DEX-treated animals at this age might be due to increased peripheral glucose uptake, yet, this remains to be established experimentally. Consistent with a previous study (31), hepatic steatosis was observed in 14-d-old animals upon DEX treatment. Whether this condition will persist until adult life and contributes to impaired hepatic insulin sensitivity remains to be determined.

The heart is a preferentially fatty acid-utilizing organ. An impressive amount of data suggest that inappropriately increased fatty acid utilization might be critical for cardiomyopathy in diabetes due to increased oxidative stress and accumulation of toxic fatty acid metabolites (11). We found that DEX administration led to increased cardiac fatty acid utilization at $2 \mathrm{~d}$ of age, as deduced from the elevated expression of genes involved in cardiac fatty acid uptake, transport, and oxidation. Elevated plasma fatty acid and triglyceride levels, especially the acute elevation of FFA concentrations, might be responsible for increased cardiac fatty acid metabolism, since it has been demonstrated that fatty acids up-regulate genes 
controlling cardiac fatty acid transport and oxidation through activation of PPAR $\alpha$ (32). Significantly increased cardiac pyruvate dehydrogenase kinase isoenzyme 4 gene expression might be induced directly by DEX, as observed in Morris hepatoma cells (33), leading to simultaneous suppression of cardiac glucose oxidation. Thus, increased cardiac blood glucose supply can only be metabolized by glycolysis since glucose oxidation is largely inhibited. At $7 \mathrm{~d}$ of age, expression most of these genes was already back to control levels. However, transient cardiac hypertrophy is prominent at this time point. Transient cardiac hypertrophy has been described in clinical trials in newborns upon GC treatment $(3,34)$ without delineation of a clear mechanisms. In the present study, we found that some genes involved in cardiac hypertrophy, such as ANF, desmin (35), and TnnT2 (36), were already upregulated at $2 \mathrm{~d}$ of age, i.e. before the occurrence of an increased heart/body weight ratio. In addition, it has been revealed that enhanced glycolysis in cardiomyocytes may elevate endothelin-1 expression (37), which is implicated in pathologic cardiac hypertrophy (38). Therefore, we assume that increased cardiac glycolysis and/or increased expression of cardiac cytoskeleton genes might be involved in the pathogenesis of transient cardiac hypertrophy caused by DEX administration. Only reduced gene expression of desmin persisted at $14 \mathrm{~d}$ of age, which may predispose to impaired cardiac function in later life, such as cardiac dilatation and heart failure (39).

In conclusion, neonatal DEX treatment has transient effects on hepatic and cardiac energy metabolism and sustained effects on plasma triglyceride and lipoprotein profiles in suckling rats. Whether these alterations predispose to hepatic abnormalities of lipid metabolism and cardiovascular disease in later life needs to be further evaluated. Although it is obviously not correct to extrapolate data from this animal experiment to human situations, data support the notion that the continued prescription of postnatal steroids should be carefully considered.

Acknowledgments. The authors thank Fjodor van der Sluijs for primer design and Frank G. Perton for skillful technical assistance.

\section{REFERENCES}

1. le Cras TD, Markham NE, Morris KG, Ahrens CR, McMurtry IF, Abman SH 2000 Neonatal dexamethasone treatment increases the risk for pulmonary hypertension in adult rats. Am J Physiol Lung Cell Mol Physiol 278:L822-L829

2. Kamphuis PJ, Croiset G, Bakker JM, van Bel F, Van Ree JM, Wiegant VM 2004 Neonatal dexamethasone treatment affects social behaviour of rats in later life. Neuropharmacology 47:461-474

3. Evans N 1994 Cardiovascular effects of dexamethasone in the preterm infant. Arch Dis Child Fetal Neonatal Ed 70:F25-F30

4. Smets K, Vanhaesebrouck P 1996 Dexamethasone associated systemic hypertension in low birth weight babies with chronic lung disease. Eur J Pediatr 155:573-575

5. Bal MP, de Vries WB, van der Leij FR, van Oosterhout MF, Berger RM, Baan J, van der Wall EE, van Bel F, Steendijk P 2005 Neonatal glucocorticosteroid treatment causes systolic dysfunction and compensatory dilation in early life: studies in 4-week-old prepubertal rats. Pediatr Res 58:46-52

6. de Vries WB, van der Leij FR, Bakker JM, Kamphuis PJ, van Oosterhout MF, Schipper ME, Smid GB, Bartelds B, van Bel F 2002 Alterations in adult rat heart after neonatal dexamethasone therapy. Pediatr Res 52:900-906

7. Barker DJ 2000 In utero programming of cardiovascular disease. Theriogenology 53:555-574

8. Holness MJ, Langdown ML, Sugden MC 2000 Early-life programming of susceptibility to dysregulation of glucose metabolism and the development of type 2 diabetes mellitus. Biochem J 349:657-665

9. Taegtmeyer H 1994 Energy metabolism of the heart: from basic concepts to clinical applications. Curr Probl Cardiol 19:59-113
10. Augustus AS, Buchanan J, Park TS, Hirata K, Noh HL, Sun J, Homma S, D'armiento J, Abel ED, Goldberg IJ 2006 Loss of lipoprotein lipase-derived fatty acids leads to increased cardiac glucose metabolism and heart dysfunction. J Biol Chem 281:8716-8723

11. Lopaschuk GD 2002 Metabolic abnormalities in the diabetic heart. Heart Fail Rev 7:149-159

12. Amin SB, Sinkin RA, McDermott MP, Kendig JW 1999 Lipid intolerance in neonates receiving dexamethasone for bronchopulmonary dysplasia. Arch Pediatr Adolesc Med 153:795-800

13. Bruder ED, Lee PC, Raff H 2004 Metabolic consequences of hypoxia from birth and dexamethasone treatment in the neonatal rat: comprehensive hepatic lipid and fatty acid profiling. Endocrinology 145:5364-5372

14. Brindley DN 1995 Role of glucocorticoids and fatty acids in the impairment of lipid metabolism observed in the metabolic syndrome. Int J Obes Relat Metab Disord 19:S69-S75

15. Nyirenda MJ, Welberg LA, Seckl JR 2001 Programming hyperglycaemia in the rat through prenatal exposure to glucocorticoids-fetal effect or maternal influence? J Endocrinol 170:653-660

16. Kuipers F, Jong MC, Lin Y, Eck M, Havinga R, Bloks V, Verkade HJ, Hofker MH, Moshage H, Berkel TJ, Vonk RJ, Havekes LM 1997 Impaired secretion of very low density lipoprotein-triglycerides by apolipoprotein E- deficient mouse hepatocytes. J Clin Invest 100:2915-2922

17. Voshol PJ, Havinga R, Wolters H, Ottenhoff R, Princen HM, Oude Elferink RP, Groen AK, Kuipers F 1998 Reduced plasma cholesterol and increased fecal sterol loss in multidrug resistance gene 2 P-glycoprotein-deficient mice. Gastroenterology 114:1024-1034

18. Bligh EG, Dyer WJ 1959 A rapid method of total lipid extraction and purification. Can J Biochem Physiol 37:911-917

19. Bloks VW, Plosch T, van Goor H, Roelofsen H, Baller J, Havinga R, Verkade HJ, van Tol A, Jansen PL, Kuipers F 2001 Hyperlipidemia and atherosclerosis associated with liver disease in ferrochelatase-deficient mice. J Lipid Res 42:41-50

20. Vandesompele J, De Preter K, Pattyn F, Poppe B, Van Roy N, De Paepe A, Speleman F 2002 Accurate normalization of real-time quantitative RT-PCR data by geometric averaging of multiple internal control genes. Genome Biol 3: research0034.1-research0034.11

21. de Vries WB, Bal MP, Homoet-van der Kraak P, Kamphuis PJ, van der Leij FR, Baan J, Steendijk P, de Weger RA, van Bel F, van Oosterhout MF 2006 Suppression of physiological cardiomyocyte proliferation in the rat pup after neonatal glucocorticosteroid treatment. Basic Res Cardiol 101:36-42

22. He J, Varma A, Weissfeld LA, Devaskar SU 2004 Postnatal glucocorticoid exposure alters the adult phenotype. Am J Physiol Regul Integr Comp Physiol 287:R198-R208

23. Huysman MW, Hokken-Koelega AC, Hop WC, Sauer PJ 2003 Effect of dexamethasone treatment on serum GH, IGF-I, and the binding proteins IGFBP-1 and -3 in ventilated very preterm infants. Pediatr Res 54:37-43

24. Smink JJ, Koedam JA, Koster JG, Buul-Offers SC 2002 Dexamethasone-induced growth inhibition of porcine growth plate chondrocytes is accompanied by changes in levels of IGF axis components. J Endocrinol 174:343-352

25. Lambillotte C, Gilon P, Henquin JC 1997 Direct glucocorticoid inhibition of insulin secretion. An in vitro study of dexamethasone effects in mouse islets. J Clin Invest 99:414-423

26. Hammon HM, Sauter SN, Reist M, Zbinden Y, Philipona C, Morel C, Blum JW 2003 Dexamethasone and colostrum feeding affect hepatic gluconeogenic enzymes differently in neonatal calves. J Anim Sci 81:3095-3106

27. Wajngot A, Khan A, Giacca A, Vranic M, Efendic S 1990 Dexamethasone increases glucose cycling, but not glucose production, in healthy subjects. Am J Physiol 259:E626-E632

28. Nicod N, Giusti V, Besse C, Tappy L 2003 Metabolic adaptations to dexamethasoneinduced insulin resistance in healthy volunteers. Obes Res 11:625-631

29. Krauss RM 2004 Lipids and lipoproteins in patients with type 2 diabetes. Diabetes Care 27:1496-1504

30. Kathiresan S, Otvos JD, Sullivan LM, Keyes MJ, Schaefer EJ, Wilson PW, D'Agostino RB, Vasan RS, Robins SJ 2006 Increased small low-density lipoprotein particle number: a prominent feature of the metabolic syndrome in the Framingham Heart Study. Circulation 113:20-29

31. Dolinsky VW, Douglas DN, Lehner R, Vance DE 2004 Regulation of the enzymes of hepatic microsomal triacylglycerol lipolysis and re-esterification by the glucocorticoid dexamethasone. Biochem J 378:967-974

32. van der Lee KA, Vork MM, De Vries JE, Willemsen PH, Glatz JF, Reneman RS, van der Vusse GJ, van Bilsen M 2000 Long-chain fatty acid-induced changes in gene expression in neonatal cardiac myocytes. J Lipid Res 41:41-47

33. Huang B, Wu P, Bowker-Kinley MM, Harris RA 2002 Regulation of pyruvate dehydrogenase kinase expression by peroxisome proliferator-activated receptoralpha ligands, glucocorticoids, and insulin. Diabetes 51:276-283

34. Boeuf B, Maragnes P, Belzic I, Lacotte J, Bonte JB, Guillois B 1997 [Glucocorticoid-induced hypertrophic cardiomyopathy in premature infants: apropos of 4 cases]. Arch Pediatr 4:152-157

35. Wang X, Li F, Campbell SE, Gerdes AM 1999 Chronic pressure overload cardiac hypertrophy and failure in guinea pigs: II. Cytoskeletal remodeling. J Mol Cell Cardiol 31:319-331

36. Frey N, Franz WM, Gloeckner K, Degenhardt M, Muller M, Muller O, Merz H, Katus HA 2000 Transgenic rat hearts expressing a human cardiac troponin T deletion reveal diastolic dysfunction and ventricular arrhythmias. Cardiovasc Res 47:254-264

37. Kakinuma Y, Miyauchi T, Suzuki T, Yuki K, Murakoshi N, Goto K, Yamaguchi I 2002 Enhancement of glycolysis in cardiomyocytes elevates endothelin-1 expression through the transcriptional factor hypoxia-inducible factor-1 alpha. Clin Sci (Lond) 103:210S-214S

38. Iemitsu M, Maeda S, Miyauchi T, Matsuda M, Tanaka H 2005 Gene expression profiling of exercise-induced cardiac hypertrophy in rats. Acta Physiol Scand 185:259-270

39. Di Somma S, Di Benedetto MP, Salvatore G, Agozzino L, Ferranti F, Esposito S, La Dogana P, Scarano MI, Caputo G, Cotrufo M, Santo LD, de Divitiis O 2004 Desmin-free cardiomyocytes and myocardial dysfunction in end stage heart failure. Eur J Heart Fail 6:389-398 


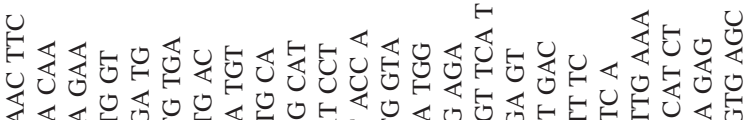

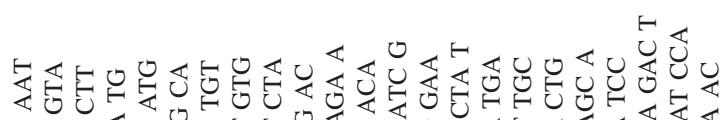

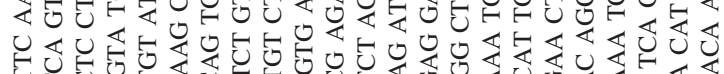

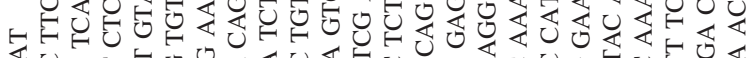

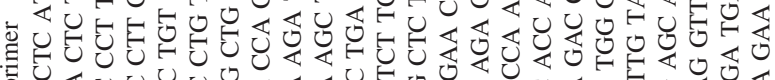

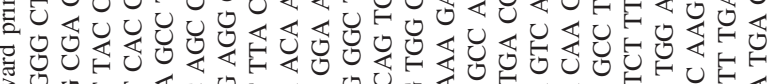

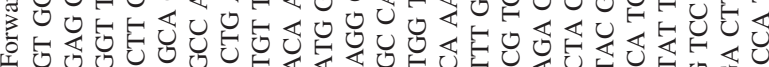

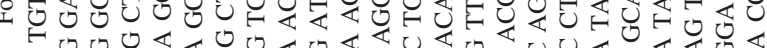

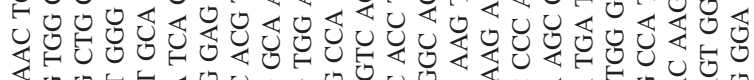

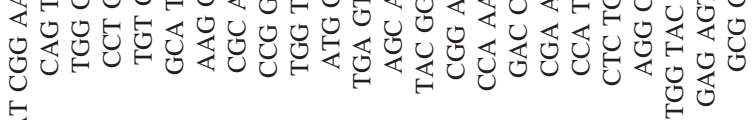
茯

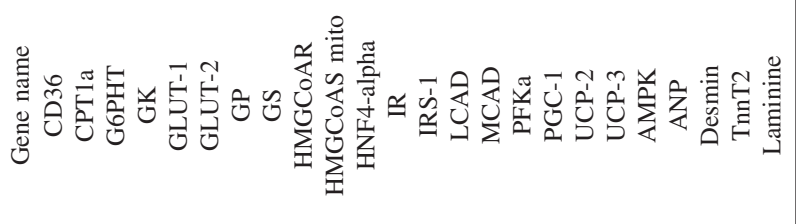

